\title{
On Different Creatural Connotations Between Two Languages
}

\author{
Diao Chen \\ College of Electrical Engineering \\ Northwest University for Nationalities \\ Lanzhou, China \\ e-mail: 383895315@qq.com
}

\section{Cai Ning}

College of Electrical Engineering

Northwest University for Nationalities

Lanzhou, China

e-mail: caining91@tsinghua.org.cn

Xue Lin

School of Foreign Studies

Beijing, China

University of Science and Technology Beijing

e-mail: ustbxuelin@163.com

\author{
Yang Chuanying* \\ College of Electrical Engineering \\ Northwest University for Nationalities \\ Lanzhou, China \\ e-mail: $991816041 @$ qq.com \\ *Corresponding Author
}

\author{
Tian Changhui \\ School of Foreign Studies \\ University of Science and Technology Beijing \\ Beijing, China \\ e-mail: tian_changhui@aliyun.com
}

\begin{abstract}
Every language is closely related to its culture. Due to historical events, cultural traditions, religious beliefs, natural environment factors, and other aspects, cultures both in English and Chinese language gives animal words specific and different cultural connotations, forming their own specific animal culture. Language is a cultural carrier and different social background and national cultures have a great effect on the cultural connotations of the animal words. Animal words reflects the moral institution, life attitude and other aspects of the national culture, and reflects the nation's social and psychological culture. Therefore, analysis of the differences between Chinese and Western animal words connotation is beneficial to understand the difference between nation's social and psychological culture, and conducive to communicate cross-culturally.
\end{abstract}

Keywords- Chinese and western cultures; Animal words; Difference; Language; Connotation

\section{INTRODUCTION}

Every language is closely related to its culture and it is not only a part of the culture but also a cultural carrier. Chinese and Western cultures are two different cultural systems and their cultural connotations are correspondingly different. Ellwood [1], at the view of cultural anthropology, thought that the language may be the first part of human culture in the early time. Language is a tool to improve human being's collaboration and a medium of all kinds of cultural interaction. It means that the relation to language and culture is far more important.

Ethnolinguistics is a comprehensive discipline span [24]. Theoretical linguistics, applied linguistics, social linguistics, psycholinguistics and language philosophy and the language of thought history research constitute the basic sector. Several of the most active branches of linguistics such as pragmatics, discourse analysis, the theory of intercultural communication, translation theory language acquisition theory and etc., all of these can obtain the ontology and methodology of resource. In other words, carrying out the study of human cultural linguistics, not only can directly involve in the field of language, thinking and culture, but also can promote and integrate the study of modern linguistics.

Human ethnolinguistics (or cultural linguistics) [5-7] is an interdisciplinary formed edge of linguistics and cultural anthropology (social anthropology). Its overlapping areas cover "language, thought, culture and their relationship" , which is the most dynamic and potential exploration in language research, and it will be applied to this essay to research the differences and connections of animal words between Chinese and western cultures.

Human beings give different cultural connotations according to the different animal words [8-10]. Although animals will never hold their own cultures, there are always some meanings for some special animals. Actually, most animals have different cultural connotations in different cultures. This paper gives the comparison of different cultural connotations of tiger, lion, deer and dog four animals, and makes an analysis of the reasons for the differences of animal words between Chinese and Western cultures.

The relationship between language, thought and culture, also known as the world view of language in the language of thought history. Its origin can be traced back to the classical period of Greece's intellectual activity. In the enlightenment campaign of eighteenth Century, Germany, French and British thinkers set the world view of language 
problems to more clear. The research on this issue is also developed to experience of science from philosophy. In the 20 s of last Century as a result of philosophical anthropology and human Linguistics rising, the world view of language has become a focus of modern Linguistics and cultural anthropology. Around this focus, the generalized academic, including linguists, anthropologists and philosophers of language, have made unremitting exploration until today, and the academic achievements and the impact of this diffuse in theoretical linguistics, sociolinguistics, psycholinguistics, applied linguistics and many other branch disciplines. Although the academic circles dominated by Western research on the relationship between language, thought and culture fruitfully for a long time, but because of its comprehensive and complex nature of this research field, there are still some theoretical and practical problems disturbing the scholars. As the development and extension of the research, there will be more new problems. However, Ethnolinguistics will be the answer of these questions.

Fettes, in Steps Towards an Ecology of Language (1996), sought "a theory of language ecology which can integrate naturalist and critical traditions"; and sought to approach a transformative ecology via a more active, perhaps designed, set of tools in language. This may cross a line between science and activism, but is within the anthropological tradition of study by the participant observer.

There are few researches on ethnolinguistics before eighties in the last century. In the 1985, on the third issue of "Journal of Fudan University" on the "Chinese dialect and Chinese culture", a dialect scholar, You Rujie first proposed the idea of establishing cultural linguistics. The author puts forward that "We need to investigate the characteristics of Chinese language in background of Chinese cultural, so as to establish a theory which can explain the Chinese language." "Combine the linguistics with other disciplines to completely change the status quo of linguistics otherworldly. In 1986, Shen Xiaolong published a "cultural method of language study". He believed that Chinese ethnolinguistics is a refutation of history, and he insisted that the "humanism" of Chinese is opposite to the "Scientism" of western language study. From the viewpoint of philosophy and culture, he pointed out that the study of Chinese cultural linguistics should be based on the cultural function of language as the object of study, and makes study of Chinese linguistics return back to Chinese itself, and build suitable Chinese characteristics of linguistics. His theory has brought shock wave of cultural linguistics, and humanities scholars are in derogatory praise difference.

In recent years, besides the cultural linguistics, there are many emerging disciplines to describe the linguistics. Liu Huanhui advocated "verbal communication" and "communicative linguistics"; Qu Yanbin advocated the "folk linguistics"; Zhao Liming put forward the "text linguistics"; $\mathrm{Hu}$ Wen Zhong introduce of "Intercultural Communication"; Wang Dechun introduce of "language and culture" (or "national cultural semantics") and so on. Obviously, not only the concept of cultural linguistics and these subjects cannot be quite distinct from each other, but also there are lot kinds of connections with the association between every research contents and methods each other.
At the same time, cultural linguistics should be one of the major family members, or cultural linguistics should be the whole "linguistics" with branches of the other researches, that is also the date of issue. Even the cultural linguistics itself how should be is also each sticks to his own view, lacking of a unified understanding, and clearly definition.

This paper is conducted out of two purposes. The first one is, there are many differences between western culture and Chinese culture. Thus, it is significant to know the differences cultures and histories. The second and the primary one is that we will study the animal words as an example through two different kinds of culture and their histories. The paper intends to make a meticulous and deep try to promote more insight in this specific field.

This paper is designed to study the following questions. (1) What ethnolinguistics methods can we use in the study of animal words? (2) Which events or activities of human history can influence our language through animal words? (3) What are the main differences between Chinese animal words connotation and English ones ?

Mainly based on Edward Sapir and the theory of ethnolinguistics, the study adopts approach to analyze the usage of some certain animal words and their sources from history, which will show us the evolutions of animal words and their formation processes.

Historical event which can influence their own culture must be an opportunity of two cultures mixed together, and one absorbed the essences from the other one. That is the significant events that we are looking for. In another way, the animal words must be common, such as dragon and tiger, existing in both cultures.

The animal words will be connected through the internet and formal essays. The explanation in dictionary is also important, and the meanings in idioms will be considered as well.

\section{AN OVERVIEW OF SIGNIFICANT CULTURES IN HISTORY}

Language and culture have evolved with the development of history. Some significant events or the formation of some kind of cultures have a profound impact on animal words, some of which will provide a connotation for an existing animal, others bring a new species even. The essay will list following six significant events or thoughts separating in two parts. All of these have great implications for animal words.

"ShanHaiChing" (the Classic of Mountains and Rivers) is one of the most important ancient writings before Chin dynasty with unknown author. The main content of ShanHaiChing contains folklore and geography, including mountains, nationalities, properties, drugs, sacrifice, witchcraft, etc. It also mentions lots of fairy tales such as the Goddess Nv Wa, the god bird Jing Wei, Kua in pursuit of the sun, King $\mathrm{Yu}$ combating the flood and so on Mythical animals are also written in the book. More than four hundred kinds of mythical animals separate around the world. Dragon and Phoenix are two of them that does not exist really.

Following myth writings have more detailed description of mythical animals, such as "Hoshin Engi", "Strange Tales from the Liao zhai Studio", the most influential of which is "Journey To the west". "Hoshin Engi" and "Journey To the west" have the same figures 
and background of fairyland, such as the king of god-the Jade Emperor, the most famous general-Erlang, and his third son Na Zha. However, "Strange Tales from the Liaozhai Studio" mostly show us the folklore scattered around, which reflect the reality of life and exposed lots of important social problems.

In China, almost all children have read the "Journey To the west" or seen the cartoons, so the Chinese ancient myths and legends have deep influence to all Chinese, and it will make sense to study in this essay.

Buddhism was built by Gautama Siddhartha, the prince of Kapilavastu (now in Nepal) three thousand years ago, and introduced into China in the late Western Han Dynasty. There are three routes that Buddhism spread in China, and the Chinese Buddhism is the most influence one. It is not a new religion of the central plains area of China, but a new thinking impacting all over the country. The Buddhism forced a plenty of areas such as architecture, literature, art, and linguistics, and bring us some new species like lion and cat.

The influence of Buddhism is remarkable. It is one of most significant background of the novel "Journey To the west". Master and prentices, altogether four of them travel to the India for the scriptures. Even the Buddha is not subject to the Jade Emperor. It is obvious that Buddhism play an important role in Chinese history.

Ancient China is a society of farming culture. That refers to a kind of custom culture formed by peasants in the long-term agricultural production, the agricultural service and farmers' own entertainment as center. Farming civilization determines the characteristics of Han culture. Chinese culture is different from European nomadic culture, in which agriculture plays a decisive role. The European civilization with predatory characteristics, which was born in the hunting culture, is obviously different from Chinese civilization rooted in the cultivation. Farming makes it possible to provide for one. People don't think highly of money, but they prefer livestock. Ten rooms and eight horses will gain the respect from other villagers, and the skill of talking means nothing.

However, farming culture also means "fed by god". Just like human needing meal, the crops need rain, under which circumstance drought means disaster. In some word, famine in farming civilization is inevitable. From the late Qing Dynasty to the early days of Liberation, lots of people dead because of famine, forcing a plenty of parents gave their kids very bad names, hoping that a bad-namekid is easy to feed. Some popular "bad name" such as $\mathrm{Hu}$ Niu (a silly girl), Tie Zhu (the iron column), Er Gouzi (the second little dog) arise spontaneously.

The Western myths are almost divided into four systems: The Olympian myth with Zeus, Hades and Poseidon; The Nordic myth with Odin, Thor and Loki; The Celt myth with the King Arthur and his Knights of the Round Table; The Hebrew myth with Michael, Gabriel and Lucifer.

These Western myths have great influence on the offspring. Saint Seiya, adaptation of the Olympian myth, has influenced our generation for a long time. Thor, the God of Thunder, has become a member of the Avengers in Marvel. The King Arthur spread knight spirit all over the Europe, making the bravery and kindness necessary to be a knight. Christianity was formed in the Hebrew culture naturally, which has influenced the whole world.

Dragon showed many times in these myths, and they will be slain or driven at the end. The existence of dragon achieves the justice, making it possible that evil can never prevail over good. That is the reason why the dragon as the symbol of evil and greedy wins support among the people. Horse, another species showing up many times in these myths, always compared with a noble knight is strong and in fast speed. It is as elegant as a knight without any dirt of village. Possibly, some knights with a style of themselves prefer to ride other animals!

The far-reaching influence of Western myth to the world is self-evident, including the western language, thinking and culture, and it is great significance to our study.

Recently more and more western fantasy novels spring up around us. World of Warcraft was born in the game of the same name. It, companied with the game, has influenced the whole childhood of a generation. The Lord of the rings, the best western fantasy movie for the last generation, is keeping on being updated. Harry Porter, written by British writer J.K. Rowling, has been translated into 67 languages, and became one of the most popular novels all over the world. A Song of Ice and Fire, lately adapted into a TV series, is winning more people's eyes.

However, all the western fantasy literatures have almost the same species: the mortal human beings like us, elegant The pretty elf with elegant stature, the tiny dwarf with a intelligent brain, the green goblin being greedy for money and lots of species with half human body and half animal body, and the enemy of all of them is the undead! The rides in the novel are more interesting, which are not limited to horses. The boars, the kodos, the chocobos, the wolves and even the velociraptors are all possible to be ridden and be good companies with their riders.

Fortunately, not all Dragon in there is evil. In the novel World of Warcraft, Azeroth, the world of story, was protected by the Five Dragon Aspects. Only one of them, Neltharion, fell and was known as the Dead Wing. Ultimately he was slain by the other four Dragons with help of Thrall, and the world fall in peace.

According to the theory of ethnolinguistics, it is important to connect the language, thought and culture each other to research. Knowing the specific historical events will help us more clearly understanding the difference in one kind of animal words between two cultures.

\section{REASONS FOR THE DIFFERENCES OF ANIMAL WORDS IN CHINESE AND WESTERN CULTURES}

The following gives comparison of the different cultural connotations of tiger, lion, deer and dog four animals. Tiger and lion are all the king of wild animals. However, due to the different habitats of these two kings, it is hard for them to duke it out. Tiger is mainly distributed in Asia and plenty of them live in China. Therefore, the tiger culture of China has been already deeply ingrained. Tiger is the most fearsome beast for ancient Chinese people, but strangely, we prefer to praise the tiger rather than slander them. Many idioms related to tiger are commendatory, like Huhushengfeng, Hutouhunao, Hubeixiongyao. Tiger is also compared with Chinese 
dragon in idioms, like Longpanhuju and Longzhenghudou. In some ancient literature, there are also many people fight the tiger to highlight their power. For instance, Wu Song, a brave and strong person, killed a fierce tiger in Jingyang hill and was famous for this.

Lion does not exist in China originally. Almost all of them come from west India before Han Dynasty. Zhang Qian journeyed to the western regions which were broadened through the Silk Road, and lots of new things like lions, were introduced into China. As a royal pet in the royal garden, Lion is rather rare in folk and naturally there is rare description. Although lion is fierce and dignified in its outlook, it is always seen as an auspicious animal. To ward off evil, people set the lions in front of the doors to press down the buildings like bank and court.

Tiger and lion do not exist in west either, but with the colonization of Africa, more and more European and English people settled in Africa and ruled the local people. As one of the local species, lion was hunted in a large number. It is also because of the strongest of the first impression, western people prefer lion than tiger. It can be obviously seen that lion is the embodiment of justice in The Lion King made by Italy, and tiger becomes the villain of the whole animation. Because of the different culture between the East and West, the king of the nature in people's hearts is also different.

In addition, deer is always considered as prey in both cultures, but in some way, the connotations are absolutely different. Hunting is one of the most primitive ways for living, and now it has been becoming an entertainment for fun or a stage to show the power. Because of the control of the guns and the protection of the animal, hunting has been disappearing in China and deer has turned to be a kind of lovely animal from prey. In ancient time, the antlers were used as weapon for the war, so the warriors who always drove the deer and obtained the antlers took more advantages. So deer also means the right to rule and power. In another way, deer is also harmonious with prosperity for Chinese, so deer has a connotation of auspice and longevity.

In western countries, hunting still exists around the Europe royalty. People prefer to use buck to describe a person who is robust and unyielding. In the National Basketball Association, Milwaukee team used the Buck as their own name to show the jumping ability. In A Song of Ice and Fire, the black crown stag is a symbol of freedom, strength and integrity. Deer can also be the most representative herbivore that is always seen as the god of nature. Malorne, as a huge white stag, the most powerful demigod in the world of warcraft, the father of the Forest King Cenarius and the spouse of the Moon God Elune, has protected the Azeroth for hundred thousand years to avoid the wars, disasters and chaos. According to that, compared with the symbol of deer that Chinese people give, western people prefer its hard power.

Refer to pets, people always think about dogs. Nowadays more and more families would like to keep dogs to eliminate the loneliness or make pleasure around the world. Most dogs have become one of the family members, but the situations are still different between China and western countries in ancient time and modern time.
In ancient China, royalty kept dogs as pets for fun just like us. There are many concubines but only one husband, the Emperor. So dogs became good companions for them to eliminate the loneliness. However, dogs were used for other function in folk. Their duty is to watch the doors and protect the house. They are regarded as a kind of domestic animals but not good friends. Thus lots of idioms of dogs are more derogatory, like Gouzhangrenshi, Goujitiaoqiang, Renmuhouyang and so on.

In western countries, things are totally different in treating dogs. Most Westerners are more random to choose animals which they like and more responsible to their pets. They believe in religions such as Christian and Catholic. Some doctrines in religion which are involved with animal care make them treat pets in an absolutely different way from Chinese attitude. Westerners would not abandon their pets and some countries even make laws to protect pets and punish their masters.

Through the above-mentioned analyses, we can recognize the great differences of the four animals between Chinese and Western culture. And just because of the difference, the world culture will be so rich and colorful. However, it is also because of this difference, there are lots of barriers in cross-cultural communication. We will obtain a better understanding of the two cultures as long as knowing these differences and only in this way can we break the cultural barriers and make communication more fluent.

\section{CONCLUSIONS}

Culture is a way for human to adapt to the nature. Environment makes animal types different from each other. Living in different environment, different people giving animal words cultural characteristics are also different. In short, there are various differences between Chinese and English animal culture, which reflect the characteristics of ethnics in thinking, aesthetic concepts and differences in culture, which is conducive to understanding intercultural communication. So understanding the plain and simple animal vocabulary usage will play an important role for us both in English reading and in understanding cultural differences.

\section{ACKNOWLEDGMENT}

This work is supported by the Fundamental Research Funds for the Central Universities of China for Northwest University for Nationalities (Grant No. 31920150007), the Zhejiang Open Foundation of the Most Important Subjects Program, the Project for Young Talents of State Ethnic Affairs Commission (SEAC) of China (Grant [2013] 231), and by National Natural Science Foundation (NNSF) of China (Grants 61263002 \& 61374054).

The authors would like to express thanks to Prof. M. J. Khan with the School of PN Engineering, National University of Sciences \& Technology, Islamabad, Pakistan and Prof. J. Cao with the Research Institute of Information Technology, Tsinghua University, Beijing, China for the beneficial discussions about this interesting topic.

\section{REFERENCES}

[1] C. A. Ellwood, An Introdution to Social Psychology, Hardpress Publishing, 2013. 
[2] E. Sapir, Language-An Introduction to the Study of Speech, New York: Harcourt, Brace and Company, 1921.

[3] E. Sapir, "Culture, Genuine and Spurious", Am. J. Soc., vol. 29, pp 401-429, 1924.

[4] L. Xue, "The application of traditional language learning strategy", J. Univ. Sci Tech. Beijing (Social Sciences Edition), vol. 6, pp. 114-116, 2008

[5] C. Kramsch, Language and Culture, Shanghai Foreign Language Education Press, 2000.

[6] E. A. Nida, Language and Culture: Contexts in Translating, Shanghai Foreign Language Education Press, 2001.
[7] D. L. Shaul and N. L. Furbee, Language and Culture, Waveland Pr Inc, 1997.

[8] L. P. Carswell, Telling the Truth About Animals: Epistemology, Ethics, and Animal Minds, Columbia University, 2004.

[9] K. Huang, "Comparative study between Chinese and Western culture in Kung Fu Panda 2," Studies in Literature and Language, vol. 6, pp. 70-73, 2013.

[10] L. Xue, "The comparison between traditional Chinese literacy strategies and English vocabulary strategies", Sino-US English Teaching, vol. 1, pp. 42-45, 2009. 